\title{
Ion-Molecule Reaction of Alkanenitriles and Transition-Metal Ions in the Gas Phase: A Study on Fragmentation Mechanism of the Adducts
}

\author{
Lin-Zhi Chen and Jack M. Miller \\ Department of Chemistry, Brock University, St. Catharines, Ontario, Canada
}

\begin{abstract}
Gas-phase ion-molecule reactions between transition-metal ions $\left(\mathrm{Mn}^{+}, \mathrm{Fe}^{+}, \mathrm{Co}^{+}, \mathrm{Ni}^{+}\right)$and propionitrile and acetonitrile were investigated. Ion-molecule adducts were prepared in a modified fast atom bombardment source and their metastable and collision-induced fragmentations, occurring in the first field-free region of an $\mathrm{E} / \mathrm{B}$ configuration instrument, were studied by means of $B / E$ linked scans. The experimental data suggest a coexistence of both "end-on" and "side-on" coordination modes; the former undergoes ligand detachment alone, whereas the latter loses methyl and ethyl radicals by insertion of $\mathrm{M}^{+}$into organic substrates and further produces ethylene via a $\beta$-hydrogen transfer. An order for the bonding energy of $\mathrm{RCN}-\mathrm{M}^{+}$is also suggested: $\mathrm{RCN}-\mathrm{Ni}^{+}>\mathrm{RCN}-\mathrm{Co}^{+}>\mathrm{RCN}-\mathrm{Fe}^{+}>\mathrm{RCN}-$ $\mathrm{Mn}^{+}$. (J Am Soc Mass Spectrom 1991, 2, 120-124)
\end{abstract}

$\mathrm{R}$ eaction of "naked" transition-metal ions with organic molecules in the gas phase has been an active research area for the last decade [1]. Ion cyclotron resonance (ICR) [2], especially the more recently developed Fourier-transform ICR [3], ion beam experiments [4], quadrupole [5] and tandem mass spectrometry [6] have been applied to this field. The latter appears most useful, since it allows the organometallic ions of interest to be isolated and further characterized by collisional activation. It should be noted that, very recently, neutralization-reionization mass spectrometry [7] has also been utilized to generate and identify stable neutral complexes [8].

Earlier studies suggest some general mechanisms for the reactions of transition-metal ions with organic molecules. The first involves insertion of metal ions into the $\mathrm{C}-\mathrm{C}$ (or $\mathrm{C}-\mathrm{H}$ ) bonds of organic substrates followed by a $\beta-\mathrm{H}$ transfer and a competitive ligand elimination, as first proposed by Allison and Ridge [9]. This mechanism has been found to prevail for many organic molecules such as alkanes, alkenes, alkhydes, ketones, esters, acids, ethers, amines, etc. Another important mechanism, often termed "remote functionalization," was first reported by Schwarz and co-workers $[10]$ in the ion-molecule reaction of $\mathrm{Fe}^{+}$ and unbranched alkanenitriles, and has since been extended to other systems like isonitriles [6c, 11], amines [12], alcohols [12b, 13], alkynes [14], allenes [14e], and ketones [15]. Basically, this involves selective activation of a $\mathrm{C}-\mathrm{H}$ (or $\mathrm{C}-\mathrm{C}$ ) bond at a position

Address reprint requests to Jack M. Miller, Department of Chemistry, Brock University, St. Catharines, Ontario, Canada L2S 3A1. remote from the functional group followed by $\beta-\mathrm{H}$ transfer or $\beta$-cleavage of $\mathrm{C}-\mathrm{C}$ bond generating $\mathrm{H}_{2}$, alkenes, or alkanes. In general, the remote functionalization occurs for "end-on" complexes. In addition, two mechanisms, "allylic" and "ion/dipole," are established for $\alpha$-branched nitriles; the former is based on insertion into $\mathrm{C}-\mathrm{CN}$ bond $/ \beta-\mathrm{H}$ shift/allylic $\mathrm{C}-\mathrm{C}$ bond cleavage [16], and the latter involves cleavage of $\mathrm{C}-\mathrm{CN}$ bond forming an ion/dipole complex followed by $\mathrm{H}$ transfer and ligand elimination [16, 17].

We recently modified the fast atom bombardment (FAB) source of our new Kratos Concept IS mass spectrometer (Kratos Analytical, Urmston, Manchester, UK) for ion-molecule reaction study (see Experimental section), and our first experiments to test the modifed FAB source were done on the ion-molecule reaction of transition-metal ions and propionitrile and acetonitrile reported previously by Schwarz and coworkers [10]. We found additional weak peaks in the $B / E$ linked spectra of the ion-molecule adducts in addition to detachment. These peaks may also have been observed by Schwarz and co-workers, but were not commented on. We were interested in these ions because they cannot be described simply in terms of remote functionalization. This article gives a possible explanation for the minor peaks and also deals with the bond energy of $\mathrm{RCN}-\mathrm{M}^{+}$.

\section{Experimental}

A Kratos Concept IS double-focusing mass spectrometer (Kratos Analytical, Urmston, Manchester, UK) (E/B configuration) was used in this work. The instru- 
ment was controlled by a Kratos DS 90 Data General Eclipse based computer system. For all studies, a nominal resolving power of 1000 was used. The spectrometer was fitted with an Ion Tech saddle field atom gun, and xenon was used as the fast-atom beam. The fast-atom beam energy was $8 \mathrm{keV}$ and the density corresponding to an emission current about $1 \mathrm{~mA}$. The source was operated at room temperature and 6 $\mathrm{keV}$ accelerating voltage. A Kratos Mach 3 data system running on a SUN SPARCstation was used for further data workup.

In a normal FAB source, it is difficult to observe the reaction of ions produced by $F A B$ sputtering with added reagents, since only a FAB probe inlet is provided. Reagents can be introduced into the source by a specially designed split probe [18], but sensitivity is low due to low pressures of the reagent sample with the open source design. Recently, some modifications to the chemical ionization (CI) sources of VG ZAB-2F [19] and ZAB-HF-3F [20] instruments for ion-molecule reaction were reported. The modified $\mathrm{CI}$ sources include apertures for the admittance of the fast-atom beam and FAB probe; the pressure inside the $\mathrm{CI} / \mathrm{FAB}$ source can be raised much higher than is usual in FAB sources, e.g., to $\mathbf{0 . 2}$ torr. In our Kratos Concept IS instrument we modified the FAB source rather than the CI source, mainly because of its simplicity. Basically, a large opening in the side opposite the entrance of the fast-atom beam is closed with a tapered stainless steel plug. Organic substrates are introduced, using a reservoir probe via the electron ionization/CI probe lock. The standard FAB source was modified to accept this probe by drilling a small hole in the source block to mate with the spring-loaded insulated probe tip. Since no accessory ionization gauge probe was available, the actual pressure in the closed FAB source was not measured. The quantity of organic sample in the source depends on the molecular leak of the reservoir probe, its temperature, and the quantity of sample injected. Commonly, a $3-\mu \mathrm{L}$ sample of liquid reagent was injected into the probe whose temperature was $100{ }^{\circ} \mathrm{C}$. Volumes could be altered to keep the molar concentration approximately the same.

$\mathrm{FeSO}_{4} \cdot 7 \mathrm{H}_{2} \mathrm{O}, \mathrm{CoCl}_{2} \cdot 6 \mathrm{H}_{2} \mathrm{O}, \mathrm{NiCl}_{2} \cdot 6 \mathrm{H}_{2} \mathrm{O}$, and $\mathrm{MnCl}_{2} \cdot \mathbf{4} \mathrm{H}_{2} \mathrm{O}$ were dissolved in water and deposited on the FAB probe tip. These salts were used to generate corresponding naked transition-metal ions by FAB. An air stream was used to cool the FAB probe in order to maintain a steady and lasting ion current. The source ion gauge pressure is typically about $10^{-5}$ torr. Metastable ion (MI) fragmentations or collisioninduced dissociations occurring in the first field-free region were monitored by $\mathrm{B} / \mathrm{E}$ linked scanning. Because the actual pressure inside the collision chamber was not measured, the $\mathrm{He}$ collision gas pressure was maintained to reduce the main beam ion current by about $20 \%$ and corresponded on average to 1.1 collisions [21]. Note that since there is diffusion of gas from the source into the collision chamber region, metastable ions for recording the MII spectra might already have been partially activated.

All samples were commercially available and used directly without further purification.

\section{Results and Discussion}

Reactions of the transition-metal ions $\left(\mathrm{Fe}^{+}, \mathrm{Co}^{+}, \mathrm{Ni}^{+}\right.$, $\mathrm{Mn}^{+}$) with acetonitrile and propionitrile produce mainly ion-molecule adducts. The adduct intensities relative to naked metal ions, which correspond to the base peaks in the mass spectra, fall between 40 and $5 \%$ and decrease in an order: $\mathrm{RCN}-\mathrm{Ni}^{+}>\mathrm{RCN}-\mathrm{Co}^{+}>$ $\mathrm{RCN}-\mathrm{Fe}^{+}>\mathrm{RCN}-\mathrm{Mn}^{+}$. Because these relative abundances of the adducts should depend on the bonding strength of $\mathrm{RCN}-\mathrm{M}^{+}$, an order of the bonding energy is suggested: $\mathrm{RCN}-\mathrm{Mn}^{+}<\mathrm{RCN}-\mathrm{Fe}^{+}<\mathrm{RCN}-$ $\mathrm{Co}^{+}<\mathrm{RCN}-\mathrm{Ni}^{+}$. The difference between the bonding energies may be explained in terms of electrostatic bonding scheme as discussed later. Dimer ions, $(\mathrm{RCN})_{2} \mathrm{M}^{+}$, are also observed for $\mathrm{Ni}^{+}$and $\mathrm{Co}^{+}$in low intensities (less than $15 \%$ relative to monoadducts). Again, the abundances of the dimer ions relative to corresponding monoadducts change in an order: $(\mathrm{RCN})_{2} \mathrm{Ni}^{+}>(\mathrm{RCN})_{2} \mathrm{Co}^{+}$. This may further prove the suggested bonding energy order.

In order to elucidate the structures of the adducts, metastable and collision-induced fragmentations were monitored in the first field-free region by means of $\mathrm{B} / \mathrm{E}$ linked scans. Figure 1 shows a typical B/E linked scan collisional activation (CA) spectrum of the complex $\mathrm{Fe}^{+} / \mathrm{CH}_{3} \mathrm{CH}_{2} \mathrm{CN}$. Release of $\mathrm{Fe}^{+}$from the complex is dominant and is observed as the sole peak in the MI spectrum. Some less intense fragments are also observed and are ascribed to losses of 15,28 , and $29 \mathrm{u}$. Similar products are also obtained for the other

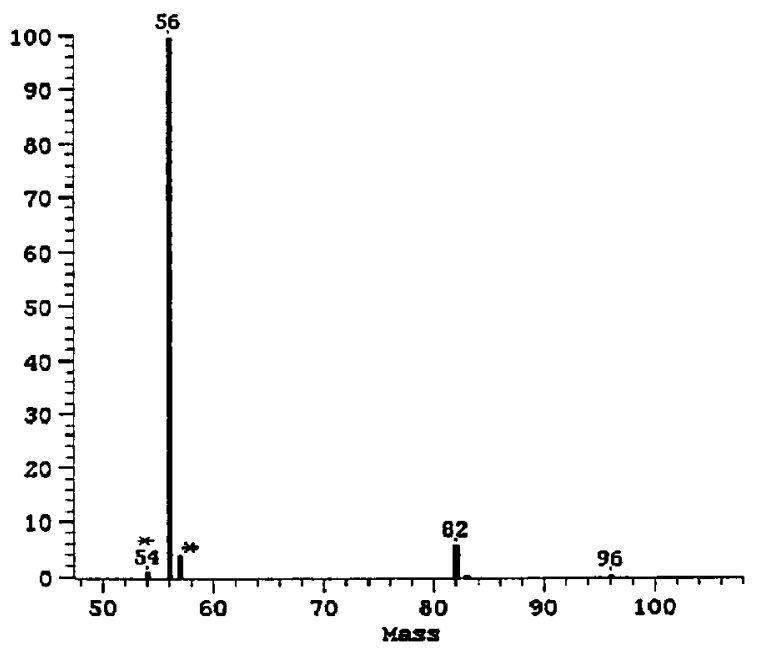

Figure 1. B/E linked scan $\mathrm{CA}$ spectrum of the complex $\mathrm{Fe}^{+} / \mathrm{CH}_{3} \mathrm{CH}_{2} \mathrm{CN}$. (Asterisks indicate artifact peaks.) 
Table 1. B/E linked scan collisionally activated spectra of $\mathrm{M}^{+} / \mathrm{CH}_{3} \mathrm{CH}_{2} \mathrm{CN}$ complexes*

\begin{tabular}{lccc}
\hline & \multicolumn{3}{c}{ Neutrai loss } \\
\cline { 2 - 4 } & $\cdot \mathrm{CH}_{3}$ & $\mathrm{CH}_{2} \mathrm{CH}_{2}$ & $\cdot \mathrm{C}_{2} \mathrm{H}_{5}$ \\
\hline \hline $\mathrm{Ni}^{+} / \mathrm{CH}_{3} \mathrm{CH}_{2} \mathrm{CN}$ & 2 & 1 & 4 \\
$\mathrm{Co}^{+} / \mathrm{CH}_{3} \mathrm{CH}_{2} \mathrm{CN}$ & 2 & 1 & 6 \\
$\mathrm{Fe}^{+} / \mathrm{CH}_{3} \mathrm{CH}_{2} \mathrm{CNN}$ & 1 & 1 & 7 \\
$\mathrm{Mn}^{+} / \mathrm{CH}_{3} \mathrm{CH}_{2} \mathrm{CN}$ & 2 & 1 & 6 \\
\hline
\end{tabular}

*Data given as the abundances of corresponding charged fragments relative to that of metal ions $\left(\mathrm{M}^{+}\right)$in the spectra: The base peaks in all cases are due to bare metal ions.

transition-metal ions, as shown in Table 1. Some artifact peaks are present, but can be easily distinguished [22]. The loss of 15, 28, and 29 u may only be attributed to methyl radical, ethylene, and ethyl radical, respectively. It is reasonable to rule out the possibility of consecutive loss of $\mathrm{H}_{2}$ and $\mathrm{CN} \cdot$ corresponding to the $28 \mathrm{u}$, because the loss of $\mathrm{CN} \cdot$ is a high-energy process [23] $\left(\Delta \mathrm{H}_{\mathrm{f}}^{0}(\mathrm{CN})=218 \mathrm{~kJ} / \mathrm{mol}[24]\right)$ and seldom occurs [25]; moreover, the $28 \mathrm{u}$ was proved to be due to $\mathrm{C}_{2} \mathrm{H}_{4}$ for complexes of long-chain nitriles [10].

Collisional activation of $\mathrm{Fe}^{+} / \mathrm{CH}_{3} \mathrm{CH}_{2} \mathrm{CN}$ in the second freld-free region of a $\mathrm{ZAB}-\mathrm{HF}-3 \mathrm{~F}$ instrument was previously investigated by Schwarz and coworkers [10]. However, they focused mainly on longchain alkanenitriles (more than 3 methylenes) and just noted that "the major product for $C_{2}, C_{3}, C_{4}$ nitriles is simply the loss of the neutral nitriles, thus producing $\mathrm{Fe}^{+} . "$ Probably because of very low intensities, the minor products were not further investigated.

Before inserting into the $\mathrm{C}-\mathrm{C}$ or $\mathrm{C}-\mathrm{H}$ bonds of the organic molecule, the metal ions undergo complexation with nitriles, since this process is expected to be the most favorable in energy and apparently occurs in most cases. If this initial complex is sufficiently long-lived, preferred coordination of the complex may play an important role in determining the final products [26]. On the basis of studies of longchain nitriles, Schwarz and co-workers [10] suggested that the $\mathrm{Fe}^{+} / \mathrm{CH}_{3} \mathrm{CH}_{2} \mathrm{CN}$ complex had an end-on structure I (Scheme I), i.e., $\mathrm{Fe}^{+}$was directly connected to the nitrogen atom and the combination of<smiles>[14CH3][14CH2][14CH2][14CH2][14CH3]</smiles>

"End-On" I

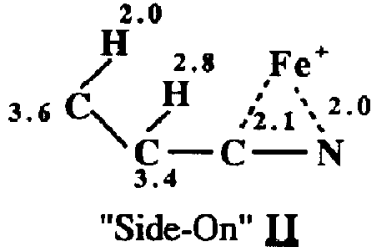

Scheme I. The numbers correspond to the distances in angstroms between each atom and the metal center.
$\mathrm{Fe}^{+}-\mathrm{NCR}$ was approximately linear. This coordination bonding is expected to be much weaker than $\mathrm{C}-\mathrm{C}$ and $\mathrm{C}-\mathrm{H}$ bonds, and cleavages occur easily either spontaneously or after collisional activation. The major fragmentation, a ligand detarhment observed in the B/E scan, can be explained in terms of structure $I$. On the other hand, the approximately linear coordination keeps $\mathrm{Fe}^{+}$far from the hydrogen and carbon atoms in the chain. Even as short a distance $[10]$ as 5.2 $\AA$ between the $\mathrm{Fe}^{+}$and $\beta$-hydrogen is still much longer than that about $2.3 \cdot 3.0 \AA$ required for metal ions to interact intermolecularly with a $\mathrm{C}-\mathrm{H}$ unit [27]. The distance between the carbon atom and the $\mathrm{Fe}^{+}$center is also longer than the required range of about 2.8-3.6 $\AA$. Obviously, the organic fragments cannot be produced from end-on complex. By referring to reactions of the transition-metal iuns with alkenes and alkynes [1d, 28], we suggest a "side-on" coordinated complex II (Scheme I) to account for the formation of these organic fragments. In the side-on adduct II, the distances of hydrogen and carbon atoms come much closer to the center of $\mathrm{Fe}^{+}$and hence make the insertion reactions of $\mathrm{Fe}^{+}$possible. Side-on coordination has been suggested for the complexation of transition-metal ions with alkenenitriles [29] and phosphaalkynes [30] and specially for the reaction of $\mathrm{Cu}^{+}$with nitriles [6a, 31]. A mechanism for the neutral losses from $\mathrm{CH}_{3} \mathrm{CH}_{2} \mathrm{CN} / \mathrm{Fe}^{+}$is proposed in Scheme II.

As the first step, metal ions $\mathrm{M}^{+}$in 1 may insert into $C_{1}-C_{2}$ or $C_{2}-C_{3}$ bond to generate intermediates 2 and 3 , followed by methyl and ethyl radical losses to form $\mathrm{M}^{+} \mathrm{CN}$ and $\mathrm{M}^{+} \mathrm{CH}_{2} \mathrm{CN}$ ions; besides, 2 can also produce ethylene via a $\beta$-H transfer, similar

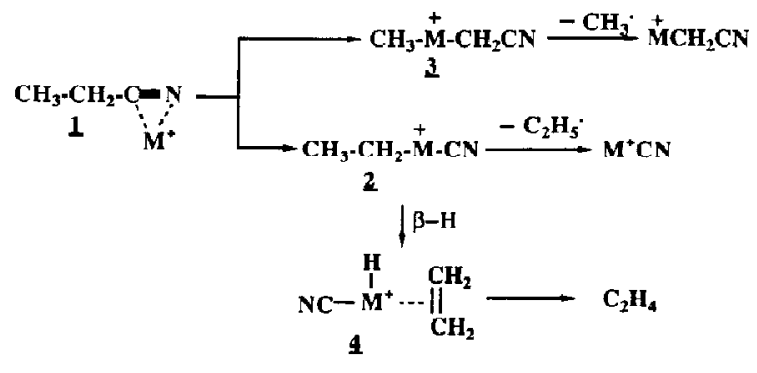

Scheme II 
to metal-alkene (alkyne) complexes. Some differences between fragmentations of 1 and $\mathrm{M}^{+}$-alkene (alkyne) complexes should be noted: the losses of $\mathrm{CH}_{3} \cdot$ and $\mathrm{CH}_{2} \mathrm{CH}_{3}$ - are not observed for the latter; instead, $\mathrm{HX}$ loss readily occurs. All the reactions of 1 producing the organic fragments, $\mathrm{CH}_{3} \cdot, \mathrm{C}_{2} \mathrm{H}_{5} \cdot$, and $\mathrm{CH}_{2}=\mathrm{CH}_{2}$, seem in competition; the loss of $\mathrm{C}_{2} \mathrm{H}_{5}$. appears kinetically favored based on considerations of the corresponding ion intensities in the $\mathrm{B} / \mathrm{E}$ spectra. Unfortunately, sufficient thermochemical data are not available, so further description of the competition is not presented here. Because the unique process observed in the $\mathrm{MI}$ is detachment, no significant insertion occurs before CA.

Insertion of metal ions into $\mathrm{C}-\mathrm{CN}$ bonds of nitriles was recently reported [16]. Although the initial coordination mode has not been clearly described, the most possible coordination may be due to side-on form. Moreover, for short-chain isonitriles, complexation with transition-metal ions is in side-on coordination mode, which corresponds to the losses of $\mathrm{C}_{2} \mathrm{H}_{5}$. and $\mathrm{C}_{2} \mathrm{H}_{4}$ [11]. Remote functionalization becomes operative and competitive as the length of the isonitrile chain increases and even dominates when the methylene number in the chain is up to 5 . The similar situation between isonitriles and nitriles suggests a coexistence of both side-on and end-on coordination modes in the complexation with transition-metal ions.

The elimination of $\mathrm{C}_{2} \mathrm{H}_{4}$ may also be described in terms of the ion/dipole intermediate, as in the case of $\alpha$-disubstituted nitriles [16, 17]. However, this requires an end-on coordination. Because the intensity of $\mathrm{M}^{+} /[\mathrm{H}, \mathrm{C}, \mathrm{N}]$ ion is very low, CA study is not available to elucidate its structure and further to prove the proposed mechanism (2-4). Even so, we prefer the insertion mechanism, since the ion/dipole intermediate cannot explain other neutral losses.

One may argue that the loss of $\mathrm{CH}_{3}$ or $\mathrm{C}_{2} \mathrm{H}_{5}$. radicals results from simple $C-C$ bond cleavage, upon collisional activation, which involves no insertion process. This seems impossible because (1) the radical loss existing for other nitriles in sector [16a], Fouriertransform ICR [6a, 16b] and ICR [26] instruments has already been described with insertion as the first step; (2) metal ions may insert into various $C-C$ bonds to give neutral products [6d]; and (3) direct cleavage of the $\mathrm{C}-\mathrm{C}$ bond in the "intact" nitrile chain is expected to involve a higher activation energy than if the $\mathrm{C}-\mathrm{M}^{+}$bond is ruptured. It is probable that the insertion of metal ions into organic molecules makes further reactions like neutral loss possible.

To support the proposed side-on coordination, reactions of the transition-metal ions with acetonitrile have also been investigated, and the results are shown in Table 2. Loss of $\mathrm{CH}_{3}$. as the sole reaction (except the ligand detachment) occurs for all $\mathrm{CH}_{3} \mathrm{CN}-\mathrm{M}^{+}$ions upon $\mathrm{CA}$; metastable fragmentation just gives $\mathrm{M}^{+}$ ions. Again, this is the result of the insertion of $\mathrm{M}^{+}$ into $\mathrm{C}-\mathrm{C}$ bond in acetonitrile, suggesting the possi-
Table 2. B/E linked scan collisionally activated spectra of $\mathrm{M}^{+} / \mathrm{CH}_{3} \mathrm{CN}$ complexes*

\begin{tabular}{ll}
\hline & Neutral loss \\
\cline { 2 - 2 }$\cdot \frac{\mathrm{CH}_{3}}{\mathrm{Ni}^{+} / \mathrm{CH}_{3} \mathrm{CN}}$ & 2 \\
$\mathrm{Co}^{+} / \mathrm{CH}_{3} \mathrm{CN}$ & 2 \\
$\mathrm{Fe}^{+} / \mathrm{CH}_{3} \mathrm{CN}$ & 2 \\
$\mathrm{Mn}^{+} / \mathrm{CH}_{3} \mathrm{CN}$ & 6 \\
\hline
\end{tabular}

*Data given as the abundances of corresponding charged frag ments relative to that of metal ions $\left(\mathrm{M}^{+}\right)$in the spectra. The base peak in all cases is due to the bare metal ion.

ble presence of a side-on coordination. Our further studies of other nitriles with longer chain also indicate a rich elimination of neutral species from the $\mathrm{RCN}-\mathrm{M}^{+}$ complexes by CA and even metastable fragmentations [32].

Finally, the complexation process deserves comment. Normally, there are two most important factors for determining the coordination geometry [26]: electrostatic and orbital interactions. The former involves dipole moment, charge distribution, polarizability, etc., whereas the latter concerns dative effect $\left(M^{+} \leftarrow\right.$ :X). Electrostatic models have been suggested for the initially formed metal ion-molecule complexes [33] like $\mathrm{M}^{+}$-nitrile [26]. This may also apply to the order of the bonding energies obtained in this study. It is consistent with an electrostatic bonding scheme. The ions that appear to bond most strongly, $\mathrm{Co}^{+}$and $\mathrm{Ni}^{+}$, both have $3 \mathrm{~d}^{n}$ ground states, whereas those that form weaker bonds, $\mathrm{Mn}^{+}$and $\mathrm{Fe}^{+}$, have $3 \mathrm{~d}^{n} 4 \mathrm{~s}^{1}$ ground states. The $4 \mathrm{~s}$ orbital is much more spatially extended than the $3 \mathrm{~d}$ orbitals, thus the latter two ions are much larger, cannot get as close to the molecule, and thus form weaker bonds. For the moment, we are unable to provide detailed description of the competitive complexation concerning both side-on and end-on coordination modes and of a possible interconversion between them. These descriptions may represent a challenge for theoretical chemistry.

\section{Acknowledgments}

The authors thank the Natural Sciences and Engineering $R$ search Council of Canada for operating and equipment grants to J. M. Miller, and thank T. R. B. Jones and D. Vukmanic for experimental assistance. We also acknowledge the editor and reviewers for suggestions.

\section{References}

1. (a) Schwarz, H. Acc. Chem. Res. 1989, 22, 282. (b) Czekay, G.; Drewello, T.; Eller, K.; Lebrilla, C. B.; Prusse, T.; Schulze, C.; Steinruck, N.; Sulzle, D.; Weiske, T.; Schwarz, H. In Organometallics in Orgaric Synthesis, vol. 2; Werner, H., and Erker, G., Eds.; Springer Verlag: Heidelberg, 1989; p. 203. (c) Russell, D. H., Ed. Gas-Phase Inorganic Chemistry, Plenum: New York, 1989. (d) Allison, J. Prog. Inorg. Chem. 1986, 34, 627. (e) Gregor, I. K.; Guilhaus, M. Mass Spectrom. Rev. 1984, 3, 39. (f) Armentrout, P. B. In Structure/Reactionty and Themochemistry of lons; Ausloos, P., and Lias, S. G., 
Eds.; D. Reidel: Dordrecht, 1987; no. 193, p. 97. (g) Ridge, D. P. In ibid, p. 165. (h) Squires, R. R. Chem. Rev. 1987, 87, 623. (i) Beauchamp, J. L. In High Energy Processes in Organometallic Chemistry, ACS Symposium Series 333; Susclick, K. E., Ed.; American Chemistry Society: Washington, D. C., 1987. (j) Jones, W. D., and Feher, F. J. Acc. Chem. Res. 1989, 22, 91.

2. (a) Allison, J.; Freas, R. B.; Ridge, D. P. J. Am. Chem. Soc. 1979, 101, 1332. (b) Frease, R, B.; Ridge, D. P.; Ibid. 1980 102, 7129. (c) Byrd, G. D.; Burnier, R. C.; Freiser, B. C. Ibid 1982, 104, 3565. (d) Kappes, M. M.; Staley, R. H. Ibid. 1982 104,1813

3. (a) Jacobsnn, D. B.; Freiser, B. S. J. Am. Chem. Soc. 1983, 105, 736. (b) Jacobson, D. B.; Freiser, B. S. Ibid, 1983, 105, 5197. (c) Jacobson, D. B.; Freiser, B. S. Ibid. 1983, 105, 7484. (d) Jacobson, D. B.; Freiser, B. S. Ibit. 1983, 105, 7492. (e) Jacobson, D. B.; Freiser, B. S. Organometallics 1984, 3, 513. (f) Jacobson, D. B.; Freiser, B. S. J. Am. Chem. Sac. 1985, 107, 72. (g) Jacobson, D. B.; Freiser, B. S. Ibid. 1985, 107, 1581.

4. Armentrout, P. B.; Beauchamp, J. L. J. Am. Chem. Soc. 1981, 103, 784. (b) Armentrout, P. B., Halle, L. F.; Beauchamp, J. L. Ibid. 1981, 103, 6624. (c) Armentrout, P. B.; Beauchamp, J. L. Ibid. 1981, 103, 6628. (d) Halle, L. F.; Houriet, R.; Kappes, M. M.; Staley, R. H.; Beauchamp, J. L. Ibid. 1982, 104, 6293. (e) Halle, L. F.; Armentrout, P. B.; Beauchamp, J. L. Organometallics 1982, 1, 963. (f) Houriet, R.; Halle, L. F.; Beauchamp, J. L. Ibid. 1983, 2, 1818. (g) Tolbert, M. A.; Beauchamp, J. L. J. Am. Chem. Soc. 1984, 106, 8117.

5. Mestdagh, H.; Morin, N.; Rolando, C. Tetrahedron Lett. $1986,27,33$

6. (a) Eller, K.; Schwarz, H. Int. J. Mass Spectrom. Ion Processes 1989, 93, 243. (b) MacMill, D. K.; Gross, M. L. In Gas-Phase Inorganic Chemistry; Russell, D. H., Ed.; Plenum: New York, 1989; p. 369. (c) Eller, K.; Schwarz, H. Chern. Ber. 1990, 123, 201. (d) Hasselbrarth, A.; Prusse, T.; Schwarz, H. Ibid. 1990, 123, 213.

7. (a) Wesdemiotis, C, McLafferty, F. W. Chem. Rev, 1987, 87, 485. (b) Terlouw, J. K.; Schwarz, H. Angew. Chem. Int. Ed. Engl. 1987, 26, 805. (c) Holmes, J. L. Mass Spectrom Rev. 1989, 8, 513 .

8. Eller, K.; Sulzle, D.; Schwarz, H. Chem. Phys. Lett. 1989, 154,443 .

9. (a) Allison, J.; Ridge, D. P. J. Am. Chem. Soc. 1979, 101, 4998. (b) Babinec, S. J.; Allison, J. Ibid. 1984, 106, 7718.

10. (a) Lebrilla, C. B.; Schulze, C.; Schwarz, H. I. Am. Chem. Soc. 1987, 109, 98. (b) Lebrilla, C. B.; Drewello, T.; Schwarz, H. Ibid. 1987, 109, 5639. (c) Lebrilla, C. B.; Drewello, T.; Schwarz, H. Int. J. Mass Spectrom. Ion. Processes 1987, 79, 287.

11. Eller, K.; Lebrilla, C. B.; Drewello, T.; Schwarz, H. J. Am. Chem. Soc. 1988, 110, 3068.

12. (a) Karrass, S.; Eller, K.; Schulze, C.; Schwarz, H. Angew. Chem. Int. Ed. Engl. 1989, 28, 607. (b) Karrass, S.; Prusse, T.; Eller, K.; Schwarz, H. J. Am. Chem. Soc. 1989, 111, 9018. (c) Karrass, S.; Eller, K.; Schwarz, H. Chem. Ber. 1990, 123 , 939.
13. Prusse, T.; Schwarz, H. Organometallics 1989, 8, 2851

14. (a) Schulze, C.; Schwarz, H. Chimia 1987, 41, 29. (b) Schulze, C.; Schwarz, H.; Peak, D. A.; Gross, M. L. I. Am. Chem. Soc. 1987, 109, 2368. (c) Schulze, C.; Schwarz, H. Ibid. 1988, 110, 67. (d) Schulze, C.; Weiske, T.; Schwarz, H. Organometallics 1988, 7, 898. (e) Steinruck, N.; Schwarz, H. Ibid. 1989, 8, 759.

15. Schroder, D.; Schwarz, H. J. Am. Chem. Soc. 1990, 172, 5947

16. (a) Czekey, G.; Drewello, T.; Eller, K.; Zummack, W.; Schwarz, H. Organometallics 1989, 8, 2439. (b) Eller, K.; Zummack, W.; Schwarz, H. J. Am. Chem. Soc. 1990, 112 621

17. Eller, K.; Schwarz, H. Organometallics 1989, 8, 1820.

18. (a) Miller, J. M.; Balasanmugam, K.; Fulcher, A. Org. Mass Spectrom. 1989, 24, 497. (b) Balasanmugam, K.; Hartman, J. 5.; Miller, J. M.; Yuan, Z. Can. J. Chem. 1988, 67, 685.

19. Freas, R. B.; Ross, M. M.; Campana, J. E. J. Am. Chew. Soc. 1985, $107,6195$.

20. Drewello, T.; Eckart, K.; Lebrilla, C. B.; Schwarz, H. Int. I Mass Spectrom. Ion Processes 1987, 76, R1.

21. Holmes, J. L. Org. Mass Spectrom. 1985, 20, 169.

22. (a) Bilton, J. N.; Kyriakindis, N.; Waight, E. S. Org. Mass Spectrom. 1978, 13, 489. (b) Morgan, R. P.; Porter, C. J.; Beynon, J. H. Ibid. 1977, 12, 735.

23. Chen, L. Z.; Flammang, R.; Maquestiau, A.; Masamba, W.; Merenyi, R.; Pommelet, J.-C.; Viehe, H.-G. Bull. Soc. Chim. Belg. 1989, 98, 529.

24. Rosenstack, M.; Draxl, K.; Steiner, B. W; Herron, J. T. J. Phys. Chem. Ref. Data 1977, 6, Suppl. 1.

25. Budzikiewicz, H.; Djerassi, C.; Williams, D. H. Mass Spectrometry of Organic Compounds; Holden-Day: San Francisco, 1967, p. 407-417.

26. Stepnowski, R. M.; Allison, J. Organometallics 1988, 7, 2097.

27. (a) Brookhart, M.; Green, M. L. H. J. Organoment. Chem. 1983, 250, 395. (b) Saillard, J.; Hoffman, R. J. Am. Chem. Soc. 1984, 106, 2006.

28. (a) Peake, D. A,; Gross, M. L.; Organometallis 1985, 5, 1236. (b) Schulze, C.; Schwarz, H.; Peake, D. A.; Gross, M. L. J. Am. Chem. Soc. 1987, 109, 2368.

29. Prusse, T.; Drewello, T.; Lebrilla, C. B.; Schwarz, H. I. Am. Chem. Soc. 1989, 111, 2857.

30. Eller, K.; Drewello, T.; Zummack, W,; Allspack, T, Annen U.; Regitz, M.; Schwarz, H. I. Am. Chem. Soc, 1989, 111, 4228 .

31. (a) Eller, K.: Schwarz, H, Chem. Ber. 1990, 123, 201. (b) Eller, K.; Drewello, T.; Schwarz, H. Organometallics 1987, 6, 2450.

32. Chen, L. Z.; Miller, J. M. Submitted.

33. (a) Bauschlicher, C. I. Jr. J. Chem. Phys. 1986, 84, 260. (b) Merchan, M.; Nebot-Gil, I.; Gonzalez-Luque, R.; Orti, E. J. Chem. Phys. 1987, 87, 1690. (c) Hankinson, D. J.; Allison, J. J. Chem. Phys. 1987, 91, 5307. (d) Hankinson, D. J.; Hooper, E. J.; Allison, J. Modeling the Electrostatic Interactions Between Transition Metal Ions and Polar Molecules. Presented at the 35th ASMS Conference on Mass Spectrometry and Allied Topics, Denver, CO, May 1987. 